\title{
Significance of Sindoor (Vermilion Powder) in Hindu Marriage Rituals
}

\author{
Bishnu Prasad Dahal \\ Correspondence: Department of Anthropology, Patan Multiple Campus, Patan Dhoka, Tribhuvan University, \\ Kathmandu, Nepal
}

Received: April 23, 2021 Accepted: May 24, 2021 Online Published: August 24, 2021

doi:10.5539/res.v13n3p76 URL: https://doi.org/10.5539/res.v13n3p76

\begin{abstract}
This paper aims to identify the significance of Sindoor or Vermilion powder (red in color) in Hindu cultural custom and in Hindu society. Sindoor is given to bride by groom on the occasion of marriage. Sindoor is given the gift by the groom to the bride in between the hair partings of married Hindu women have begun to start on the day of the marriage ceremony and the married woman. After then she considered as the wife of her husband and enters to the matrimonial life. Use of Sindoor in Hindu marriage practices signify socially culturally and even medically to order the gender disequilibrium society through the symbolic interpretation of cultural item and traditions, values, norms that are interwoven by religious bind with the member of Hindu orthodox society to sustain the patriarchal social structure. Sindoor also signify the hierarchy among the women world and the status changes when an unmarried wears a Sindoor in Hindu Society
\end{abstract}

Keywords: Hindu marriage, patriarchy, Sindoor, tradition, custom, women, sexuality, ritual

\section{Introduction}

Culture according to Geertz is also not a force or causal agent in the social world and culture consists of such pattern of meanings which embedded in symbols, while social structure comprises the "economic, political, and social relations among individuals and groups" (Geertz, 1973b). For Geertz, culture is "an historically transmitted pattern of meanings embodied in symbols, a system of inherited conceptions expressed in symbolic forms by means of which men communicate, perpetuate, and develop their knowledge about and their attitudes toward life" (Geertz, 1973c).

Ethnographies are also interpretations (Geertz, 1973d). In anthropological explanations, ethnographies are not mostly used as scientific evidences and its empiricism are not tested and approved by quantitative data. They are mostly interpretations, or misinterpretations, like any others, arrived at in the same way as any others (Geertz, 1973d). Geertz used the cockfight as text enables to bring out an aspect of it to describe the Balinese world to the learner that might otherwise go unnoticed: "its use of emotion for cognitive ends" (Geertz, 1973a). The ethnography of Balinese cockfights is an emotional education for Balinese - it teaches and reinforces the emotions and reactions of Balinese culture in an external text through which Geertz defined culture his general statement as the culture of a people is an ensemble of texts, themselves ensembles, which the anthropologist strains to read over the shoulders of those to whom they properly belong (Geertz, 1973a).

Marriage as a micro-social institution is defined as a socially acknowledged and approved sexual union between two adult individuals and the function of marriage is to create family. It is also the kind of understanding or a contract which is bound by legal and somehow customarily rules and regulations. Marriage is an important relationship, which is socially approved and is defined and sanctioned by custom and law. There is problem while defining the marriage anthropologically, because there is no definition which adequately covers all types of human marriage of this world. Among these definitions the definition put forwarded by Edward Westmark is found more comprehensive among other definitions as marriage is "the more or less durable connection between male and female lasting beyond the mere act of propagation till after the birth of offspring". According to Robert H. Lowie, "Marriage is a relatively permanent bond between permissible mates"(Westermarck, 1906). Marriage is a socially sanctioned union of male and female for the purpose of establishing family, socially approved sexual relations between partners, procreating and rearing of the offspring.

Functionalists begin with the importance of marriage as formative social institutions that play a key role to maintain the social stability, social harmony and social integration. Through the establishment of marriage bond the family is created. The family members perform certain systemic functions that facilitate the prosperity and development of society. Functionalist argued that there are four universal residual functions of the family: sexual, reproductive, educational, and economic. 
Marxist theorists focused on social institutions reproduce systems of inequality and conflicts as simple as the enforcement of rules from parent to child, which in turn perpetuate gender inequalities. Marxist feminism, examine domestic violence (spousal and child), sexual assault, marital rape, and incest and theorize how these disproportionate, violent acts against women and girls provide a home for sexism and violence (Engels, 1988). According to Marx and Engels, patriarchy (through marriage) maintains the oppression of women and children, as they have less control over resources and are therefore less powerful. To destroy family, one must first undermine or weaken that unique and powerful bond between husband and wife, and put a wedge between children and parents (Engels, 1988). Sexual experimentation is encouraged by the State - the goal is to bring an end to monogamy - all in the name of freedom and equality.

\subsection{Hindu Marriage Practices}

In Hindu society, marriage is a micro-social institution in which there are formal legal and socially accepted bond between two individuals. Hindu marriage rituals and customs are varying in terms of the region, caste, and clan, even though there vast dissimilarity that found in the rituals processes, procedures, natures and many more that are associated with marriages throughout Hindus of Nepal. Marriage is a micro-social institution which helps to establish the bond between partners to begin their new life. During marriage rituals performance or ceremonies there are various performances and processes with their own norms and values and each has its own importance and significance. Among them, Sindoor Dan as most important custom of Hindu wedding that holds a special significance and the groom puts Sindoor (red vermilion powder) in his bride's hair partition, to legalize the marriage and socially established that symbolizing her marital status.

In Hindu marriage ceremonies, putting Sindoor in bride's forehead is not just a ritual, but it signifies a symbolic meaning which usually associated with the long life for the husband. In Hindu orthodox society, patriarchy acts as a system in which women are subordinated, oppressed, discriminate and unequal in terms of resource allocation, opportunity share and power relations with the help of the static, structural micro-social institutions through socio-cultural settings (Dahal, 2020b). Hindu wedding is a sacred institution for entering for the bride and groom where they spend their love life together forever. Marriage custom and ritual accomplishes with enough religious and cultural beliefs of putting Sindoor are major essences with its relevant mean for marriage ceremony. Now a day, in modern marriage Sindoor has given utmost value as previous holds. Hindu marriage is filled with colorful ceremonies making it an extravagant and lavish affair to unite matchmaking couple in a holy union.

Sindoor is made by using turmeric, mercury and lime which is a red in color and in powder form. In Hindu mythical cultural taboo or tradition, Sindoor stands as a symbol of status of married woman which also helps to assist on controlling blood pressure, regulate and stimulate functions and activeness of her mind's activities. But the associations of such cultural symbols manifestly signify the using Sindoor (vermilion powder) until her husband alive. But latently, it also signifies the status of woman as married women brought other society through marriage in a groom's village. Usually, mother-in-laws and daughter-in laws of that particular society only can bear Sindoor for that society because they are brought from another society through marriage. During a wedding, groom puts Sindoor in the forehead of his better half by parting hair and is never applied by unmarried women or widows that are associated with the significance of the Hindu marriage. It is associated with female power and sexuality. Sindoor is first put on woman's forehead by her husband on the day of her wedding, and becomes a daily ritual thereafter. Now, women have adopted different ways of wearing Sindoor - at the beginning or along the parting line or as a red spot on the forehead.

\subsection{Importance of Sindoor in Hindu Marriage}

Culturally, the Sindoor as a precious gift that is given to bride by groom in the marriage ritual ceremony has an important role to maintain the marriage bond, to establish the familial relationship between families of bride and groom and it is also a kind of exchange in which one society establish the relations with another which is socially accepted and also considered to be sacred and auspicious by married Hindus, their families and society. Sindoor is one of the cosmetic item that is wore by women to see as she became beautiful after the wearing of it and the cosmetic item is also used as decorative role for Hindu women . Religiously, the red color usually expresses the symbol of fertility and perceived auspicious and it has wider religious significance in Hindu society. Structurally, the Sindoor is prepared using mercury, turmeric and lime. Traditionally, Sindoor was used to prepare by mixing and moistened with lime juice, iodine, and camphor with oil, sea shell powder kasturi and sandalwood (Kapoor, 2007). Sindoor can also be made with sandalwood which is mixed with musk and a mixture of saffron flower (Kapoor, 2007). During the preparation of Sindoor alum is mixed with lime and turmeric; it changes the yellow to red color and Mercury helps in lasting the red color and, imparting the red color to the Sindoor (Kapoor, 2007). Nowadays Sindoor is being commercially manufactured by big capitalist brands (Kapoor, 2007). The manufacturing process of Sindoor involves different materials, chemicals, synthetic dyes and mercury sulphite. The one of the components of the Sindoor is mercury which 
acts as a catalyst that helps to release stress and strain, also helps in keeping the brain active and alert. Importantly, mercury also helps in controlling blood pressure, activating sexual drive and libidinal energy. This is why; a widow or an unmarried woman is forbidden from applying Sindoor.

In Hindu culture women have been subjected to wearing Sindoor over their foreheads to showcase their position as a respectable daughter-in-law in households. The application of Sindoor has been a very important part of structuring a woman's personality and it is related with sexuality too after marriage. It is suggested that the red color symbolizes power and fertility.

\section{Theoretical Review}

This research article is about significance of Sindoor in Hindu marriage, but it is also about the best way to study Hindu social and cultural context related with marriage ritual and wedding ceremonies using insights from the interpretive tradition in anthropology and discipline which studies the human behavior especially symbolic interactionism (Blumer, 1986) and neo-Weberian comparative-historical sociology. The interpretation of meaning requires using our ability to "understand" other human beings, cultures and associates and people who may be far away from the society where ethnographer studied by participating the particular culture in their worldview. While studying the religion and marriage especially Hindu marriage and its significance anthropologically, it provides a clear picture to analyze the of the system of meanings embodied in the symbols associated within that cultural world and it also acts as the mechanism to maintain the social order within the diverse and conflicting components which helps to perform such rituals to express their own particular meaning in Hindu marriage rituals that make up the religion or spiritual system of Hindus related with marriage processes and marriage items associated with particular cultural meanings, and the meaning that disseminated by cultural items were associated with these systems to social-structural and psychological processes (Geertz, 1973d).

Symbols of religion usually functions to maintain the social order through the events, processes, that are inter weaved with various components of social structure and cultural components associated with the realities of everyday life accepted by means of religious faith that bound with the cultural taboo, religious processes and the things that matter to people more than anything else, with transcendent truths, with another mode of existence. In religious ritual (consecrated behavior expressed in dramatic ceremony), of the actor or the performer the members of that society experience a symbolic fusion of ethos and world view (Geertz, 1973d) and they perceived the cultural values and norms of that particular culture by participating in the ritual "attain their faith as they portray it" (Geertz, 1973d) and from that people made their own standpoint in that particular cultural system what they understood and what they wanted to do and feel that they should do (their ethos / dispositions) joins with their picture of the way the world actually that helped to make perceptions, attitudes with the help of their own knowledge system associated with everyday life that mostly help to (their worldview/metaphysical conceptions) shape their spiritual consciousness through metaphors.

While studying the anthropology of meanings of symbols and the processes that mostly associated with the myth and ritual through which humans assign meanings to these symbols in order to address fundamental questions about meaning of human social life. Sometimes people try to find out the symbolic meaning of those particular cultural components in terms of cultural purity and cultural impurities, sometimes through the cultural events, processes or more. In most of these cultural scenarios the people usually want to identify the cultural significance in relation to these components through the maintaining social order of that particular social context associated with the cultural elements interweaved with the events, processes and their significance.

Religious rituals affirm that all aspects of human life have symbolic meanings associated with the particular events and that there are human responses to problems of meaning and they provide resources for finding meaning at its level by using sacred symbols that create an image of a sacred order that are binding either socio-culturally or religiously that relate the "problem of meaning" to a sphere larger than the empirical world by dramatizing the responsive meanings through the use of sacred symbols in ritual and showing that threats are interpretable and meaningfulness can be achieved again. As parallel with the Turner's phrase "symbols are multi-vocal in nature" the duty and responsibility of anthropologist to study the cultural symbol to understand the "webs of significance" of it, focuses on the socio-cultural and religious associated meaning of behavior primarily ties with the everyday life and that meaning rely primarily on verbal data in support of their interpretations. Likewise, the ideas of Geertz in his "thick description" also aim to interpret the meaning of behavior to explain actions and attitudes of that particular culture of particular people, which consists of "structures of significance", "frame of interpretation" or "socially established structures of meaning" (Geertz, 1973d) to elaborate the culture as "context" and the object of the anthropologist is to describe it. But, in case Hindu marriage rituals, the aim of this paper is to explore the significance of Sindoor in Hindu marriage practices and the interpretation of meanings that embodied in it. 
According to Geertz in Hindu religion Sindoor is perceived as a system of symbols of marriage which acts to establish powerful, pervasive, and long-lasting moods and motivations in member of the society by formulating conceptions of a general order of existence of social structural hierarchy of married and unmarried. Through the symbol of married women who wear Sindoor as the symbol of fertility which is assumed as danger for those men, women and other members of society who perceived the Sindoor wearer should not communicate with the other male members and other members without the permission of her husband and any form of the patriarchal annexes that exist in the family and society. That's why as parallel with Geertz, these conceptions with such an aura of factuality that the moods and motivations seem uniquely realistic" (Geertz, 1973c). Geertz then breaks down his definition to examine exactly what the study of marriage religion as a cultural system in Hindu society should be. That's why, in this context, the important aspect of symbols of Sindoor in Hindu marriage is that marriage symbols are models - and importantly, both models of and models for (Geertz, 1973c). Systems of symbols function similarly; that is, systems of symbols act as models of reality and models for reality. So, use of Sindoor in Hindu marriage system must be perceived as "uniquely realistic"; i.e., this feeling should be the ground-level interpretation of a Hindu culture in which people even if the learner may not be Hindus, but when he or she needs to find meaning at its deepest level, through which he or she will learn the meaning of Sindoor which helps to understand the Hindu culture as the system of symbols.

While defining the symbol by Turner he used the term as the smallest unit of ritual which retains specific properties of ritual behavior" (McGee \& Warms, 2012). As juxtaposed with the Turnerian model of symbolic analysis(1967) in elaborating the significance of Sindoor in Hindu marriage rituals it is also important to keep interpretative and observational events, processes, cultural and marriage procedures and materials associated with Hindu cultural system to separate when examining them. From the study of Significance of using Sindoor in marriage by Hundus, it is found that, each ritual has is designed with its own meaning, that should be studied deeply. It is also found that these symbols are used to show the role of patriarchy, to control over the fertility, mobility and sexuality of women through the socio-cultural system associated with the Hindu religion. So, Sindoor stands as the dominant symbols of Hindu marriage through which men ruled over women in Hindu society to maintain a constant dominant identity. Sindoor signify the female fertility in ritual context to illustrate the significance of Hindu marriage ritual interpretation to explain the domination of patriarchy.

Mary while in the study of such interpretation of symbols should not limit as only the cultural events through the study of ritual practices, or socially constructed events, and she defies the generalization of the one cultural events to the other that most symbolic anthropologists fail to describe culture as universal (McGee \& Warms 2012). According to Douglas "body symbolism is part of the common stock of symbols" and "rituals draw on those commons stock of symbols selectively" (McGee \& Warms, 2012) and her theoretical approach emphasizes the mental categories that would provide individuals with a psychological ordering of the world (Miller, 2002). For Douglas, in Hindu caste system there are the division of labor is affected. There is division of labor on the basis of ascribed status i.e.- by birth. The concept of pure and pollution is associated and the holiest member of such a system comes into contact with nothing that might "pollute" them, where individuals prescribed the job of cleaning away excrement such as blood or feces are considered to be the lowest on the social ladder (McGee \& Warms, 2012). Likewise, the rules of marriage ceremonies are also enforced and the one of the best example of such symbolic interpretation of such religious cultural component is the - Sindoor.

Habermass in his critical standpoints concludes that while changing society and culture the basic structure of socio-cultural patterns that are legitimated by religion and custom are weakened by the capitalism- industrialization, modernization, globalizations (Ritzer, 2000). Now a day, because of expansion of market, public sphere is also expanded and people can debate, discuss about obey and disobey such socio-cultural values, norms, rules and regulations that enforced by the religious institutions and cultural components. But such life experience of people, family, community, society which are played as basic structure of the people's life by governing overall socio-cultural system are more concentrated on economy rather than socio- cultural issues and life (Ritzer, 2000). So, it is declining day by day and techo-economic sectors are getting high value and more priority in society, that's why such cultural, religious values are declining day by day and the use of Sindoor by married women in Hindu society, is one of the example.

It is found that, applying Habermas concepts of the critical theory in studying the significance of Sindoor in Hindu cultural system by married women is a result of their limited conception of the way that knowledge is connected with human interests. I have seen two main kinds of interest. Firstly, instrumental interest, the concern with the domination of nature of the purpose of satisfying material needs by using Sindoor. This interest also involves the domination of men and patriarchy over women in order to dominate, control and organize them in to the required household and village economic activity. Secondly, the emanicipatory interest, the desire to socialize all kinds of dominations, exploitation and oppression of which was institutionalized through the cultural and religious values, norms and attitudes that women can accepts easily (Ritzer, 2000). 
Consequently, in societies like Hindus such cultural communication through symbols has built into it a discrepancy between those conditions required for the full exercise of reason and the reaching of truth, and those which govern how people actually interact with each other in such cultural system. It is obvious that people want to move from the actual to the ideal condition. In many ways, it calls for further realization of the ideal of democracy by creating an effective public whose free discussion about such cultural practices is neither institutionally constrained nor subverted by the handing the power of male domination and patriarchy over female to impose such discriminations, oppression and inequalities to exploit women in the name of preserve, conserve and follow such cultural practices in Hindu society.

According to Habermas, the integration of a society depends upon a balance between system and life world processes. In modern society state and its associates are helping through creating that balance where as in traditional societies micro social institutions are acting as an agents (Ritzer, 2000). According to Habermas, there are three different types of interpretive patterns in the life world; first is, actors possesses implicit and shared stocks of knowledge about cultural traditions, values, beliefs, linguistic structures and their use in interaction (Ritzer, 2000). Second is, they also know how to organize social relations and what kinds of patterns of coordinated interactions are proper and appropriate. Third is, they understand what people are alike, how they should act, and what is normal and abnormal.

According to Habermas, these three interpretative patterns helps to perform certain functional needs for reproducing life world; 1) Reaching understanding through communicative action serves the function of transmitting, preserving and renewing cultural knowledge.2) It helps to create social integration, solidarity and cohesion through social interaction. 3) It helps to know own personal identity (Ritzer, 2000). Thus, three components of the life world - culture, society, and personality- meets corresponding needs of society-cultural reproduction, social integration, and personality formationthrough three dimensions along which communicative action is conducted- reaching understanding, coordinating interaction, and socialization. These life world processes are interrelated with system processes in a society. That's why some accepts and follow to wear Sindoor and some rejects to wear Sindoor after marriage in Hindu society.

As parallel with Talcott Parson's analytical distinctions among personality, social and cultural system to the process of interaction, "a system is relatively structured certain functions need to be fulfilled for a system to survive". AGIL ( any system of action only exists in so far as four basic needs are at least in past fulfilled by four types of functions" (Ritzer, 2000). For Habermas, people use linguistically articulated patterns as well as more implicit knowledge about cultures, society and personality in their day to day interaction i.e. through indigenous knowledge system (IKS). Habermas has made les mysterious and vague the life world as it has been conceptualized by phenomenologist and ethno-mythologists. For example, cultural understanding through symbols, society, social organization and personality through self and ego is possible. Can Bali social life be possible to understand only through the cockfight? Can status of women in Hindu society be possible to understand through the Hindu marriage practices especially the Sindoor?

So, the primary objective of the study was to identify the significance of Hindu marriage rituals in Hindu society as a symbol of Hindu society and factors associated with these rituals. The specific objectives of this paper are to identify the functions of the Hindu marriage rituals to satisfy the socio-cultural needs of the Hindu society in individual level, institutional level and in moral level where society can integrate despite others disintegrated things. Here the main objectives of the research is to identify both manifest and latent function of Hindu marriage rituals and meaning embodied in it to maintain the social order in family and society because there are wide gap between genders, caste, ethnicity, role, responsibilities and power of members of the society. That's why such cultural events, processes and procedures manifestly functions as the mechanisms to celebrate such religious rituals through which members of a society feel, engage and participate in entertainment but to know how it helps to maintain the social order, socio-cultural integration, harmony, cohesiveness through interactions and exchange although there are diverse elements in family, society and in Hindu world. Under these circumstances I would like to identify the significance of Sindoor in Hindu marriage practices.

\section{Methodology}

To identify the significance of Sindoor in Hindu marriage practices in Hindu world were studied by using participant observation methods where dominant Hindu high caste especially Brahman, Chhetri and Hindu religious people with other ethnic and religious people celebrate Hindu marriage rituals practices predominantly. Methodologically, Hindu marriage rituals and practices are the part of psycho-cultural phenomena and within these cultural practices in the base of religion; there are many functions of Hindu marriage rituals practices both manifestly or latently.

The field work of this research was conducted in Kathmandu in 2019 where Hindu marriages were celebrated. The descriptive and explorative research designs were designed to collect the information as per the required. During the course of study, explorative research design helped to gather the information related with the causal relationship between marriage rituals, use of Sindoor, people's perceptions, socio-cultural patterns and its associations with everyday life and Hindu world view. The descriptive research design helped to describe the marriage ritual, socio-cultural settings, 
and significance of such marriage events in Hindu cultural world with their meanings. Both quantitative and qualitative data were collected with the help of open ended interview, structured interview and semi-structured interviews among total 20 respondents. Respondents or participants were the bride or groom. The respondents were selected on the basis of the criteria that who are bride or groom in Hindu marriage rituals practices at the time.

\subsection{Interview}

Semi-structured, open-ended interview, key informant interview were conduct to gather the information about Hindu marriage, marriage procedures, processes and ceremonies with respondents, their family members and elders who have depth knowledge on research topic. Usually, Hindu priest, marriage match maker were asked questions related to key information which verify the information gathered from the respondents.

Interviews were conducted to respondents about the Hindu marriage rituals practices, marriage procedures and use of materials during marriage and especially Sindoor and its significance in Hindu marriage ceremony.

\subsection{Participant Observation}

Purposively bride and groom of Hindu marriage rituals practices were selected for respondents. I was participated the Hindu marriage events as observer and observed whole marriage rituals, procedures, processes and significance with meanings through observation methods. Researcher is also a member of the particular society where research was conducted. As an observer researcher has tried to maintain the ethics so as to easy to visualize the Hindu marriage rituals and events and its symbolic meaning and its significance in Hindu society without biasness. Through the participant observation researcher gathered the various marriage events such as details about marriage events, processes, procedures of 20 respondents. Specifically, the marriage ceremonies in significance to use the Sindoor in Hindu marriage practices and its scope, limitation, significance were studied during the field work as researcher as observer. Similarly, the Sindoor was used as the symbol of social acceptance of bride by the groom and their parties by maintain caste hierarchy. Observation was conducted to find out the inter relationship between socio-cultural events with their everyday life pattern to maintain the social order and social equilibrium by maintain the status quo of bride and groom parties. Observation also has also helped to explore the reason behind such cultural practices associated with what, when, how, whom, why questions or dimensions in relation with the significance of Sindoor in Hindu marriage rituals practices? Actually, why this Hindu marriage rituals practices is continuously celebrated despite various problems and criticized by the feminist and activists?

\section{Findings and Discussion}

In Hindu marriage customs, the ritual of Sindoor use is one of the most important traditional practices in Hindu wedding ceremonies. Manifestly, Sindoor stands as only a symbol of a married woman but it has latent but a profound significance. Wearing Sindoor begins on the day of marriage and through Sindoor a male, patriarchy, and whole Hindu society, dictate their oppressive, discriminatory and unequal rules, roles, duties, responsibilities, opportunities etc. with the newly married women as her marriage lasts. Through Sindoor on her forehead, the men dominate the women and her marital status is confirmed by it. In Hindu society, the most common ideas of people or members of the society is that Sindoor stands as the signs of marriage worn by a woman ensure her husband's long life and it is referred to the security that this sign of marriage brings to women in society both idealistically and realistically.

\subsection{Hindu Religion, Marriage Practices and Sexuality}

In Hindu society socio-cultural norms discourage young men and women from regular private interaction (Caldwell et al. 1998). However, this may have more to do with cultural tradition, kinship terms, and caste endogamy but clan exogamy marriage associated with the religious proscriptions regarding premarital sex. Hindu marriage is regarded as life course of different stage of socialization, because without marriage men cannot get a wife and he cannot enter the Grihasth Ashrama (the life stage of a householder) and without marriage people cannot get socio-cultural approval of sex relation and there can be no offspring, and without a son, no release from the chain of reincarnation in birth-death-rebirth. Hindu orthodox system basically, constructed and controlled by the religious philosophy of patriarchy. Women's sexuality is directly controlled by the men through the religious, social and cultural barriers which is discriminative in nature even if the sexuality of women differences as the age of maturity. The code of sexual conduct for the householder -husband fully endorses the rules and regulation with the various socio-cultural norms guided by the Hindu orthodox religion to establish the norms of patriarchy. Men, patriarchy and senior women (as agent of masculinity and patriarchy) usually controls over female sexuality in the name of marriage signify symbolically through the accessories mostly Sindoor.

\subsection{Knowledge, Attitudes and Perception of Hindu Women Towards Wearing Sindoor}

Marriage is solemnization of two souls and Sindoor is usually worn by the married women as mark of being married or as a mark of her custom \& traditions. In Hindu society there are various acts, traditions and customs that always respect 
the women's faith towards marriage subjected the Sindoor but it is subjected to the betterment of woman in the society to give her freedom of expression to live not to impress anybody but to express herself. Though, Hindus follow the traditional ritual wedding during the social marriages in Hindu society. So, is Sindoor, a losing traditional practice among the modern Hindu women finding its oddness with Western outfits?

It would be inappropriate to mention that every married Hindu lady has discarded the traditional usage of vermilion, but the numbers are in declination due to access of modernistic outlook among them. Many Hindu modern women usually wear Sindoor as an optional fashion that goes with their dress style. On instances, the woman ignoring vermilion in Western wears can use it when draped in a sari during the certain family ceremony. Gradually, using and wearing Sindoor by Hindu women is changing their fashion, item from Socio-culturally compulsory to optional to determine the status of marital status to a Hindu woman. But, with the increase of education and many other development reasons in Hindu society of Kathmandu the use of Sindoor is decreasing and only limited to use in the exceptional cases among the modern literate women.

\subsection{Patriarchy and Oppression of Women's Sexuality}

In Hindu orthodox society, a woman is treated like a sex object and the father gives her away at the wedding to the husband who must henceforth bear all her responsibilities and she wears signs of marriage in consent. Through the feminist perspective the Sindoor is a symbol of creating discrimination among women world and with men too. Sindoor signify the symbol of slave of husband for married women sexually and she is sexually available to just for husband when he feels desires. But the situation and relation is reverse when a woman wants to establish such relation with her husband. So a married woman is viewed as an object rightfully owned by her husband, she must bear proof of his authority. It indicates strongly uneven power dynamics between the sexes which persist in a marriage between them.

There are numerous arguments that approve of the use of gender-specific signs of marriage, and those who defend the Sindoor by the obvious feeling of ease it provides not to fear and a woman can only hope to be safe if she willingly prioritizes her identity as someone's wife before she can speak in the capacity of an individual whose marital status is so unimportant that it is rendered useless. Their argument is part of the larger societal expectation which makes a woman identify herself in relation to a man by apply the Sindoor. Since women are considered inferior units in the family and society with little or no respect for their distinct identity, no matter what their accomplishments.

Marxist feminism argued the male dominance and patriarchy usually control over women because of production and (re)production. The concept of 'production' and 'reproduction' is the central theme of Marxist within the feminist discourse. Mostly, sexual division of labour and the organization of gender relations prevailing within the family and in a larger social structure are the byproducts of market based production economy and surplus making through the reproduction or by the production intensification (Craib, 1990). The conceptual framework for analyzing 'production' and 'reproduction' is the inter linkage between production and reproduction in the light of maintenance and perpetuation of women's subordination which is guided by the relationship between the market and family, between the production of things and the production of people and between patriarchy and capitalism. In patriarchal social structure and in Hindu orthodox cultural system, women's separate identities are not socially and culturally accepted to accommodate and they must be given a less scary shape under the shadow of women's legal male partners and she made re-signification of the Sindoor possible and that is what irked the guardians of the Hindu morality. If the Sindoor is only worn for its aesthetic appeal by women regardless of their marital status, it would cease to be the signifier of male authority over women. The rituals, customs and practices we have perpetuate the myth of male superiority and women's inferior position in society and the Sindoor as signs of marriage, in Hindu society can extend the conflict with women's self-hood and their experiences that are so often inconsistent with their marital status.

\subsection{Sindoor; A Symbol of 'Blessed' Marital Status}

Sindoor (vermilion) acts as a symbol for Hindu married women from time immemorial. Hindu married women wear Sindoor on their forehead of their middle-parted hair as cultural identity reflects the desire of the longevity and success of one's husband, ideologically. Hindu astrological beliefs present the meaning of Sindoor as a symbol of good luck or 'saubhagya'.

Sindoor is one of the key ingredients for most of the Hindu rituals or customs as well as one of the important items of Hindu bridal cosmetic and which has also spiritual significance attached to them and therefore is very popular among Hindu devotees. There are certain reasons that these materials are considered so holy in Hinduism and are also considered an essential material in Hinduism as it is a cultural identity of any married Hindu women. It forms an inseparable part of her life. Sindoor is a married woman's crowning glory and it is got by God's blessing, which has always dreamt of. Culturally, red is the color of power, energy, and is a symbol of fertility and it is used as a legacy to show a woman's devotion towards her husband. 
Red Sindoor powder is thought to have medicinal properties that benefit women, including stimulating blood flow to trigger their sex drive - the reason why unmarried women and widows are not allowed to wear it in the Ayurvedic herbology although, a woman's choice is for historical, spiritual or medicinal reasons, a unifying thread is that, traditionally speaking, the end goal is to please men - be it a husband or the wider patriarchy.

\subsection{Significance of Sindoor}

The Sindoor (vermillion) is red, a color that signifies power and passion. Traditionally, Sindoor is made of organic or natural and herbal substances like turmeric, lime, alum, mercury or saffron. Sindoor is the symbol of fertility and since progeny is one of the aspects of a marriage. Ancient belief suggests that Sindoor consisting of mercury was used in the olden days to stimulate the reproductive organs to boost fertility and also keeps the blood pressure and stress under control. Sindoor was used to apply from the forehead to the point of the pituitary gland which regulates most of the bodily functions and boosts well-being by stimulating the hormone-secreting glands.

\subsection{Myths Associated With Use of Sindoor}

Mythically, from the interaction with key informants and Hindu priests, it is found that, wearing Sindoor by Hindu women is deeply rooted with the Hindu myths associated with the Mahabharat in which Radha turned her Sindoor into flame in her forehead and Daraupadi abandoned to wear Sindoor disgusting and despairing the Sindoor when she was lost by Pandav (her 5 husbands) in Hastinapur.

According to the mythical story, goddess Parvati or Sati stands as chaste and ideal wife and honest towards her husband Lord Mahadev or Shiva. That's why Parvati wore Sindoor as symbol of honor to her husband. So, every married Hindu women wear Sindoor as show her honor to her husband and loyalty with him and every Hindu married wife is supposed to emulate goddess Parvati and wear Sindoor and Hindu world view believe that if women wear Sindoor Goddess Parvati automatically protect their husbands. So, the Sindoor as red color is the symbol of female energy and power.

Sindoor helps to have a good healthy life helping marital bliss. Sindoor also helps to prohibit the relations of married women with other men except her husband and in a way it is to let others know the one's marital status to other in case of Hindu women, so that no one proposes the married women for marriage and extra marital relationships. Sindoor also stands as the sign of respect towards the state of union and love for her husband. Hindu women stay fasting for their husband's well being and long life. Such affections, love, devotions help to strengthen their marriage bond and also affects fortune of their partners and their married life. So it is believed that the husband of such devotee and loyalty of wife surrounded as a protection web of safety for her husband. Red color in Hindu religion is supposed to significance of love and passion through which women can win the heart of men.

According to the mythical definition of Hinduism, marriage is such a bond between husbands and wives, which can be strongly bonded, loyal with each other, love and take care with each other themselves but could not show because of shyness and so they maintain their relationships, harmony, etc. latently but only through the Sindoor they can express in public manifestly. Without Sindoor Hindu married women become incomplete, so Hindu women fill their forehead with full of joy, happiness, smiles and well wishing for her husband. Sindoor is a symbol of 'blessed' marital status and most glorious symbol of success in life of any Hindu married women.

\section{Case study- 1}

The women of Hindu orthodox society of Kathmandu expressed her opinion and attitudes towards the perception of women in Sindoor, as "If I don't wear Sindoor, it feel strange and like a widow. It was used to believe that Sindoor must be applied for the husband's long life. I also fear my husband may suffer harm if I don't wear Sindoor" said Juneli [pseduname] who works for professional job in Kathmandu. She does not like to wear Sindoor, but in family I should wear compulsory in family gathering, marriage ceremonies and in such special occasion. That's why I occasionally wear in cultural gathering of family. There's clearly immense societal pressure on women to conform to the role of the 'good wife' not just in action but also in appearance.

\section{Case study- 2}

Namita [pseudoname] shared her opinion in terms of significance of Sindoor as; if women of Hindu society don't use Sindoor how one can identify the female whether she is married or not? She laughs innocuously when asked how unmarried men can be distinguished from their married counterparts, when one has Sindoor and go outdoors, she doesn't face any (street sexual) harassment because it shows women are married and in patriarchal society single woman gets harassed all the time, that's why Sindoor has great significance as a symbol of marriage.

In patriarchy, men do not need to change their marital status because they won't go away from their natal home after marriage (they do not change residences after marriage situation), they don't change their surnames either etc. During the fieldwork, in Kathmandu, it was found from the study that, a woman is groomed to become a good fate wife 
(Saubhagyabati) and widowhood is the worst fate in Hindu society for women. All cultural and ritual customs including Sindoor, are designed to pray for the husband's long life. The red Sindoor(Vermillion powder) is mostly a derivative of cinnabar which is a naturally occurring form of mercury sulfide.

\subsection{The Reasons behind the Wearing Sindoor}

In Hindu society in Kathmandu, every culture has different symbols of marriage among them some of them wear Sindoor. It is natural that, the women while in status of bride in wedding day look beautiful with all the heavy jewelry and makeup and she looks completely changed after her marriage because her getup has changed forever, but the man looks exactly the same as he was before marriage. The symbolic practices of the Hindu rituals which bind the lives of a married woman and it also restrict them to bind within their limits of mobility, sexuality and social behavior.

These practices of wearing Sindoor by women of Hindu society should be what she decides to wear and not are controlled by the patriarchy and male dominant ideology or masculinity. Such obligation about wearing is decided by the Hindu religious norms, values and customs. In another way, the obligations to wear married symbols for women deny the woman autonomy and make her submissive towards the pre-defined notions of patriarchy which explains how a "good" wife ought to be. Here the role of the patriarchy and social construction and cultural symbols that are construed socio-cultural norms of the freedom of choice for the women, but unfortunately, the Hindu society has also normalized these marriage symbols and glorified them in present context.

The socio-cultural, economic, religious dependencies of women with men ultimately justify the dependence of women with men. That's why dominance of men and patriarchy in micro-social institutions like family, marriage, kinship, economic activities and so on were found profound and wearing Sindoor by married women of Hindu society of Kathmandu was found compulsory and mandatory because of Hindu cultural values and economic, cultural, social dominance of men over women.

\subsection{Anthropological Analysis}

Sindoor stands as the cultural symbol of the identity of a married Hindu woman. The gift Sindoor is specially given first in the wedding ceremony to the bride by the groom becomes her partner in each and every moment. The identity of bride in newly married women in new residence is associated with the groom, which was through her father in natal home. The Sindoor is not only the denotative of a woman's marital symbol women but it is a cosmetic item through which patriarchy and male dominance is enforced in Hindu Society. The Sindoor acts as the item through which women follow the customs and traditions of Hindu society and culture in which people are satisfying the needs of the society (Bhattacharya, 2013). In Hindu marriages, the groom smears red Sindoor on the bride's forehead which signifies the marriage bond, love sharing and it also signify the color of passion and married women in Hindu culture is seen as sexually desirable and passionate because widows are exempted from applying Sindoor as their bodies only belonged to their husbands. The color of red also signifies the color of blood and which is also symbol of fertility and reproduction (menstrual blood), by attaining puberty, a woman can able to reproduce and she becomes more sexually desirable. The remarkable changes that can be seen in women after puberty, shows that she enters into womanhood and not only physical but emotionally a woman is getting matured, so, her interests on such cultural events also signify the importance of using Sindoor after marriage. The Sindoor also brings changes to a woman's life and it makes her husband's property. '

Sindoor creates hierarchy among the women for different status. In filiafocal practice women who wore Sindoor stands as less privileged hierarchal status than women who do not wear Sindoor. The Sindoor is not only to differentiate the women by married of unmarried, it also create different socio-cultural, legal, economic etc. status, role, hierarchy and opportunities too.

Sindoor is treated as an ornamental mark of marriage, but Hindu norms and values completely shun the existence of Sindoor as a response to the patriarchal society, she should compulsorily wear in cultural and social function if she is married and women aren't appreciated if they do not want to wear it and they are not treated as the humble wife the society expects them to be. The age-old views started to change when feminist movements had shaken up women's opinions on their own bodies and culture. Sindoor was soon caught in a huge crossfire where one side consisted of old traditions trying to reestablish their cultural beliefs and the other side consisted of an upcoming age of women who wanted to defy patriarchal views of the society.

In modern society, Sindoor lost its relevance a progressive woman steps out while wearing Sindoor is shunned for being 'overly conservative' while a woman, who chooses not to wear it, is socially constricted by others of the same age group and some of them also thought that avoiding to wear Sindoor ultimately pressurize and facing unruly judgments and who don't wear them, in fear of being socio-culturally stranded. Now a day, most of the Hindu married women wear Sindoor as cosmetic purpose which also signify the cultural and social values and even the values of patriarchy but they 
have been recreating uses and colors of Sindoor in many concepts to prove that Sindoor, is in fact not a dated concept, but something that is evolving constantly. Even though its primary goal had been to please men, it has now progressed into classical ways of empowering women's choices and their opinions.

Even in today's liberal world where women can express their own interest, can create their own identity, for a married Hindu woman, the Sindoor signifies the sexuality of women, creates hierarchal order, and signify her desire for her husband's long life and prosperity and is also considered a sign of her never dying love and devotion towards her better half under patriarchy. On the other hand, with modernization during certain religious festivals, wearing Sindoor is customary for a husband to apply it on his wife's forehead though the style, content, color and quantities may vary. Now a day some brides choose to fill in the entire hair line when parted, while others prefer putting it in the form of a dot right at the starting point of the hair partition. All signify the same.

\section{Conclusion}

Wearing Sindoor for women of Hindu society signify the woman is highly committed to her husband and the Sindoor is a sign of auspiciousness; it shows her devotion, love, care and loyalty of wife towards her husband, patriarchy and the Hindu cultural system and similarly the man on the other hand does not wear such kinds of any of the symbol to show the love, loyalty and devotion towards his wife (Bhattacharya, 2013). In Hindu cultural system, widows and unmarried girls are exempted or restricted to wear Sindoor because Sindoor is associated with fertility of woman in one hand and the public information about her husband still alive. It is a cultural internalization that a woman undergoes from a young age or stage to maturity. On the day of marriage, the bride is adorned with Sindoor she decorated with cosmetics, and socialized with the great sincerity towards the husband, his family and patriarchy. The role of woman changes after getting Sindoor and her places also changes in Hindu society. So there is a popular proverb that "Daughter for others' home to decorate". In another word, Sindoor provides women opportunity to handle the socio-cultural in Hindu society. Then after she is loyal to her married home and gradually away from the natal home bond and should submit herself to her husband and becomes his property. Sindoor signify socio-culturally married differentiate a woman as in two categories; virgin (pure, holy) and married (impure and polluted ) role in Hindu cultural role after receiving Sindoor a woman enters from a girl to fertile life. She is submitting her body to her husband, free labor power to her husband's family and her fertility and reproducing for her husband's next generation.

\section{References}

Bhattacharya, A. (2013). Hindu Bengali Women: The Symbols of Marriage. in Yakalı-Çamoğlu Dikmen, On Gender and Love: Inter-Disciplinary Explorations, Inter-Disciplinary Press Oxford, United Kingdom, 73-90. ISBN 978-1-84888-206-5.

Blumer, H. (1986). Symbolic Interactionism: Perspective and Method. University of California Press.

Caldwell, J. C., Caldwell, P., Caldwell, B. K., \& Pieris, I. (1998). The Construction of Adolescence in a Changing World: Implications for Sexuality, Reproduction and Marriage. Studies in Family Planning, 29, 137-53. https://doi.org/10.2307/172155

Craib, I. (1997). Classical Social Theory, London: Oxford University Press.

Cuff, E. C., Sharrock, W. W., \& Francis, D. W. (1990). Perspectives in Sociology. Third Edition, Unwin Hyman Ltd. London.

Engels, F. (1988). Origin and Evolution of the Family. Population and Development Review, 14(4), 705-729. https://doi.org/10.2307/1973630

Geertz, C. (1973a). Deep Play: Notes on the Balinese Cockfight. in The Interpretation of Cultures, 412-453. New York: Basic Books.

Geertz, C. (1973b). Person, Time, and Conduct in Bali. in The Interpretation of Cultures, 360-411. New York: Basic Books.

Geertz, C. (1973c). Religion as a Cultural System. in The Interpretation of Cultures, 87-125. New York: Basic Books.

Geertz, C. (1973d). Thick Description: Toward an Interpretive Theory of Culture. in The Interpretation of Cultures, 3-30. New York: Basic Books.

Kakar S. (1989) Intimate Relations: Exploring Indian Sexuality. Chicago, New Delhi: University of Chicago Press, Penguin Books India (P) Ltd.

Kapoor, V. P. (2007). Kohl and Sindoor: The potential source of lead poisoning, EnviroNews, 13(3), 5-7.

McGee, R. J., \& Warms, R. L. (2012). Anthropological Theory an Introductory History. (5th edition). USA: McGraw-Hill. 
Miller, B. D. (2002). Cultural Anthropology. $2^{\text {nd }}$ edition. Boston: Allyn and Bacon.

Ritzer, G. (2000). Sociological Theories. (5th ed.). Mc Graw, Hill International Editions.

Turner, V. (1967). The Forest of symbols: Aspects of Ndembu ritual. Ithaca, London: Cornell University Press.

Westermarck, E. (1906). The Origin and Development of the Moral Ideas, Macmillan and Company, Limited.

\section{Copyrights}

Copyright for this article is retained by the author(s), with first publication rights granted to the journal.

This is an open-access article distributed under the terms and conditions of the Creative Commons Attribution license (http://creativecommons.org/licenses/by/4.0/). 